\title{
Innovative Thinking on the Supervision Work from the Ideological and Political Perspective
}

\author{
Yin Jian ${ }^{1, *}$ Song Jianmei ${ }^{2, b}$
}

\author{
${ }^{1}$ School of Basic Science, Shengli College China University of Petroleum,Dongying,Shan dong257000,China \\ ${ }^{2}$ Dongying Shengli No.1 Junior Middle School, Dongying, Shan dong257000, China \\ *Corresponding author. Email: 999a666@163.com
}

\begin{abstract}
The cultivation of students' feelings of home and country outside their professional study is an important value embodiment of the implementation of "curriculum ideology and politics", New teachers lack of teaching experience, there is a general lack of teaching design ability; Key teachers are generally too casual in the implementation of the teaching plan; There are realistic challenges in the development of curriculum ideology and politics; Two levels of supervision and development should be set up to improve teachers' ability of ideological and political teaching in the curriculum.
\end{abstract}

Keywords: course education, the supervision work, innovation

$$
\begin{aligned}
& \text { 课程思政视域下督导工作的创新思考 } \\
& \text { 尹健 } 1, \mathrm{a},{ }^{*} \text { 宋健美 } 2, \mathrm{~b} \\
& \text { 1中国石油大学胜利学院, 东营, 山东, 中国 } \\
& { }^{2} \text { 山东东营胜利第一初级中学, 东营, 山东, 中国 } \\
& \text { a999a666@163.com, b1411498332@qq.com } \\
& \text { *尹健 }
\end{aligned}
$$

中文摘要：对于学生在专业学习之外家国情怀的培养，是实施“课程思政”的重要价值体现。 新进教师教学经验不足, 普遍存在着教学设计能力欠缺的问题; 重点听课教师普遍在教学计 划的执行上过于随意; 课程思政的开展存在现实挑战。要设置两级督导并进方式，着力提升 教师课程思政教学能力, 从信仰生成角度, 打造课程思政生成机制。

关键词: 课程思政; 督导; 创新

\section{1. 引言}

新冠疫情当前, 抗疫勇士们的逆向而行令人敬佩, 也让我们回想起朱光潜先生曾给武汉大学毕业生的题 词: “个人温饱以外, 别无高尚理想, 士当引以为耻。”
对于学生在专业学习之外家国情怀的培养, 是实施“课 程思政”的重要价值体现。全国高校工作会议指出: “要重视对学生道德素养的培育, 将思想政治教育工作 落实到具体教学环节中, 并渗透到各学科之内, 实现 多角度全方位的育人，努力开创我国高等教育事业发 展的全新局面”。这一重要思想的提出不但为我国思政 
新教师也中存在着学生学情把握不准等情况, 使教学 预期与实际效果存在出入，不能及时调整教学进度; 新教师的教学进度前松后紧, 出现赶课现象。

从教学内容上看: 课程思政意识较为薄弱。推进 课程思政是教育部门工作的重要内容, 只有少部分教 师在授课过程中注意了这一点, 多数教师还是在传授 知识点方面下功夫比较大。在这一点上, 老教师做得 比较好, 不仅在课堂上教授知识, 还将自己的正确的 人生观、价值观、世界观融入教学之中, 教导学生成 人成才。年轻老师还须进一步提升授课艺术, 要从知 识、思想和灵魂等多方面育人。

从教学方法上看, 多数教师还欠缺尝试不同教法 的勇气, 课堂模式还相对较单一。有的老师在教学中, 学生还不清楚的问题也直接提问, 导致课堂气氛尴筴, 使课堂由题“满堂灌”变为“满堂问”, 由“满堂灌”变为 “满堂探”, 由“不发言”变为“乱发言”, 看上去互动环节 比较多, 实际效率并不高。

另外, 案例教学、情景教学等能真正把学生带起 来、让学生动起来的课堂教学方式运用率还不高, 导 致课堂气氛活泼和思维活跃程度各异。通过对教师教 学手段是否灵活多变进行观察发现, 多数课堂教学中 鲜活的生活案例或创设活生生的工作情境进行教学的 相对较少。这个问题同时存在于老教师和青年教师中 间。

\section{4. 课程思政背景下督导工作的创新}

\section{1 设置两级督导并进方式}

往往文化的素养形成是由亲属、地域、传统习惯 构成的制度体系获得的 ${ }^{[2]}$, 对于教学督导机制而言也 是如此, 完善的机制建设是教学顺畅运行的基础。

首先, 从普遍意义上说, 各教学院系的督导组要 完善设置, 有序开展工作。建议明确隶属关系, 充分 发挥教学督导的作用。校级教学督导和教学院督导的 结合, 对新教师、评价较低教师由学校督导完成, 遴 选教师的日常教学秩序检查、适时课堂教学巡视、教 学计划教案试卷的检查等建议放在二级教学督导工作 中。

其次, 建议量化督导数据, 实施分级分类管理。 每学期根据评教结果区间对教师授课实施分类管理。 一是对教师授课门数进行“正常、限制、暂停”等分级 管理, 引导教师结合自身的教学能力上好每一门课, 授课过程始终存在问题、督导评价一直较低的教师实 行暂停授课管理; 二是对教师听课方式进行“专门听 课”“随机听课”“免听课”三类管理, 重点跟踪短板教师 的教学状况。有鼓励有惩戒, 以此激发教师授课的价 值展现，同时督导员积极挖掘“导”的内涵和作用，减 少“督”的分量和影响, 使教师对教学督导组专家的督 导, 不是畏惧、反感, 而是接受和欢迎, 以此体现教 学督导的有效度。 
如何成人”的探索, 促使学生在专业学习过程中实现能

再次，深入学习世界高等教育当前的发展方向和 先进的教学方法, 按照我国当前评价“金课”的标准修 改课程思政课堂评价的重点。特别是在由教师主讲和 学生主体的转化工作中, 还需要多做出顶层设计。对 新老督导员进行常态化培训, 提供尽量多的机会在听 课结束后集体就某位老师的听课情况探讨、交流。

\section{2 着力提升教师课程思政教学能力}

针对课程思政角度的督导评价, 教学管理部门应 与教学院系配合, 建立有效反馈机制, 发挥“以督促导” 的真正作用, 达成教学的最优化, 切实提高课程思政 课堂教学的质量和效果。

首先, 加强青年的教师先进的教育思想和教育模 式的学习, 推动信息化、翻转课堂、雨课堂等混合式 教学等先进的教学组织形式和教学方法的改革。让更 多的老师学会运用国家的教学资源平台辅助教学, 既 便于教学数据的收集和分析, 也有利于保存今后申报 一流课程方面所需要的数据。

其次, 重视教师实践能力的培养。高校教师多数 毕业于研究型大学, 理论功底扎实, 实践能力相对较 弱, 不利于提高实践教学的质量, 应鼓励教师积极参 与提高实践能力的各种学术活动和培训交流。

再次, 鼓励教师之间成立教学改革团队, 学校给 予政策支持, 特别是加快建设团队中的梯队结构, 让 老教师的经验与新教师的信息技术相结合, 实现优势 互补, 达到在课堂教学中的强强联合。利用多媒体进 行教学研究近年来已经有了较为丰富的经验 ${ }^{[3]}$, 新教 师掌握信息技术用于教学相对较多, 而老教师在这个 方面涉及较少, 新老教师教学团队的结合可以互相弥 补, 教有所长。

另外, 还应同步完善“教师评学”评价体系, 建立 即时反馈机制。不仅及时掌握教师在教育教学中产生 的问题, 也要及时掌握学生在学习过程中存在的学风 问题, 让学生明确督导听课对学风的评价标准, 内化 于心, 让督导听课不仅“督教”, 还要“督学”, 以师生 通力合作共同完成“意义创生”[4]。促进教与学的双方实 现共同发展。

\section{3 从信仰生成角度, 打造课程思政生成机制}

首先, 充分发挥大思政格局的全方位育人功能, 深入挖掘专业课程中蕴涵的思想政治教育内容, 促进 专业课与思想政治理论课同向同行, 实现价值引领、 知识教育和能力培养的有机统一, 并在这个基础上给 予思政教师和专业课教师从操作技能到教学理念的帮 助和提升, 以求培养出勤勉好学、坚韧自强, 具有民 族风骨和时代担当的高素质人才。

其次, 引导专业课教师在国际视野、国家需要、 区域发展、学校定位和个人价值等方面对专业课程进 行全盘思考, 在专业教学中贯穿“何为人、成为何人、
力、素养的生成性自主建构。

再次, 将课程思政的现有研究从个案的感性认识 阶段上升到系统的理论研究阶段, 并在这个基础上给 予思政教师和专业课教师从操作技能到教学理念的帮 助和提升。引导教师主动思考如何将群体的教学活动 转化为个体学生的自觉行动, 形成相对完整的专业课 程思政教学体系。

课程思政的实施如果不能进入学生生活体验层面, 效果可能适得其反。只有打破长期以来思想政治教育 与专业教育相互隔绝的“孤岛效应”，才能将立德树人 贯彻到高校课堂教学全过程、全方位、全员之中 ${ }^{[5]}$ 。 通过正确引导专业课教师对课程中思政内涵的挖掘, 拉近课程内容与学生生活的距离, 推动知识传授、能 力培养与理想信念、价值理念、道德观念教育有机融 合, 在大思政格局下对专业类课程教学组织形式进行 实质性变革, 以专业案例丰富思政课程, 督导工作就 真正实现了督导目的, 亦即最终帮助教师塑造出富有 创造性、充满人文关怀、师生共同成长的课堂。

\section{致谢}

本文为 2019 年度山东省艺术科学重点 课题 (综合研究专项) 《中国道路”视阈下 清河区抗战文化研究》（ZH201906006）、 2019 年中国石油大学胜利学院教学研究项 目《对分课堂: 高校思政课教学模式的创 新与实践研究》（JGZD201915）阶段性成 果之一。

\section{REFERENCES}

[1] Velery Tishkiv,U.S. and Russian Anthropology:Unequeal Dialogue in a Time of Transition, Current Anthropology, pp.1-18,1998,39(1).

[2] Anthony Giddens. The Consequences of Modernity. Stanford University Press, pp.113, 1990.

[3] Malik, K., Martinez, N., Romero, J., et al. MixedMethods Study of Online and Written Organic Chemistry Heomewoork[J].Journal of Chemical Education. pp.18041809, 2014(91).

[4] Karolich,R.,\& Ford,J. Applying Learner-centered Principles to Teaching Human Behavior in the Social Environment in a Baccalaureate Program[J].Journal of Teaching in Social Work, 2013(1): 26-40.

[5] $\mathrm{Xu}$ Tao. To construct the general pattern of ideological and political education, DOI:http://theory.people.com.cn/n1/2019/1018/c4053131406699.html. 